\title{
Is the poleward migration of tropical cyclone maximum intensity associated with a poleward migration of tropical cyclone genesis?
}

\author{
Anne Sophie Daloz ${ }^{1}$ (D) Suzana J. Camargo ${ }^{2}$
}

Received: 29 November 2016 / Accepted: 16 March 2017 / Published online: 3 April 2017

(C) Springer-Verlag Berlin Heidelberg 2017

\begin{abstract}
A recent study showed that the global average latitude where tropical cyclones achieve their lifetimemaximum intensity has been migrating poleward at a rate of about one-half degree of latitude per decade over the last 30 years in each hemisphere. However, it does not answer a critical question: is the poleward migration of tropical cyclone lifetime-maximum intensity associated with a poleward migration of tropical cyclone genesis? In this study we will examine this question. First we analyze changes in the environmental variables associated with tropical cyclone genesis, namely entropy deficit, potential intensity, vertical wind shear, vorticity, skin temperature and specific humidity at $500 \mathrm{hPa}$ in reanalysis datasets between 1980 and 2013. Then, a selection of these variables is combined into two tropical cyclone genesis indices that empirically relate tropical cyclone genesis to large-scale variables. We find a shift toward greater (smaller) average potential number of genesis at higher (lower) latitudes over most regions of the Pacific Ocean, which is consistent with a migration of tropical cyclone genesis towards higher latitudes. We then examine the global best track archive and find coherent and significant poleward shifts in mean genesis position over the Pacific Ocean basins.
\end{abstract}

Keywords Tropical cyclone genesis · Poleward migration $\cdot$ Tropical cyclone genesis index $\cdot$ Observations

Anne Sophie Daloz

adaloz@wisc.edu

1 Space and Science Engineering Center, University of Wisconsin-Madison, 1225 West Dayton Street, Madison, WI 53706, USA

2 Lamont-Doherty Earth Observatory, Columbia University, Palisades, NY, USA

\section{Introduction}

Kossin et al. (2014) showed that in the past few decades (1982-2009) the large-scale environment of tropical cyclones has evolved over the tropics and subtropics. Indeed, favorable conditions for the development of tropical cyclones have migrated towards higher latitudes (vertical wind shear and potential intensity), moving from the tropics closer to the subtropics. With a globally homogenized record of intensity (Kossin et al. 2013) and a global besttrack archive (Knapp et al. 2010), they also demonstrated that the location where observed tropical cyclones reach their maximum intensity has been migrating towards higher latitudes. More recently, Kossin et al. (2016) used observations and simulations to examine the changes in lifetimemaximum intensity and tropical cyclone exposure for the present and future climates over the western North Pacific Ocean. The projections of tropical cyclones were simulated by, and downscaled from, an ensemble of numerical Coupled Model Intercomparison Project Phase 5 (CMIP5) models (Taylor et al. 2012). They showed a poleward migration of lifetime-maximum intensity (LMI) latitude in the present century and continuing into the future using one of the representative concentration pathways (RCP8.5). A possible mechanism responsible for these global and local changes is the expansion of the tropics (Lucas et al. 2014), however this link has not been proved yet.

The current study expands on the findings by Kossin et al. $(2014,2016)$ by analyzing the possible origin of the poleward migration of the LMI latitude. More precisely, we would like to answer the following question: Is the poleward migration of tropical cyclones' LMI location related to a poleward migration in tropical cyclone genesis location? Tropical cyclones are very sensitive to the large-scale environment both during their genesis and development 
stage. A reasonable hypothesis is that the poleward migration of the favorable large-scale environment would modify not only the position where tropical cyclones reach their maximum intensity but also shift the location of tropical cyclone genesis to higher latitudes. A recent study by Colbert et al. (2013) showed that changes in the large-scale environment of tropical cyclones could modify the genesis location, leading to changes in the occurrence of recurving storm tracks.

Kossin et al. (2014) argues that by restricting their analysis of tropical cyclone data to the lifetime-maximum intensity only, instead of the full storm track, mitigates the uncertainty existent in observed tropical cyclone data. In this study we consider observed tropical cyclone genesis, therefore reintroducing some inherent uncertainty in our analysis. Indeed, the reliability of the tropical cyclone tracks archives is problematic as discussed in many studies (e.g. Kamahori et al. 2006; Lander 2008; Knapp and Kruk 2010). One well known problem of observed TC tracks is the presence of data inhomogeneity due to the introduction of aircraft and satellite observations. Therefore, we will restrict our analysis to the period after 1980 in order to mitigate these biases. Another important issue is that several centers use different averaging periods for measuring tropical cyclone wind speed, as well different thresholds for genesis. Here we will use a common global threshold in our definition of tropical cyclone genesis as explained in Sect. 2. As storms are more accurately monitored at their peak than at the beginning of their lifetime, when they are weaker, we are aware that considering observed tropical cyclone genesis data has its caveats. Therefore, we also analyze the possible changes in environmental variables and tropical cyclone genesis indices in order to increase the robustness and confidence of our results.

Previous studies have investigated the relationship between climate and tropical cyclone activity using indices that relate large-scale environmental conditions to the number of tropical cyclone genesis. These indices are known as genesis indices and are based on the empirical relationship between several environmental factors and the occurrence of tropical cyclone genesis. Gray (1979) developed the first genesis index, called genesis potential (GP) index. The predictors included sea surface temperature (SST), mid-level relative humidity, vertical wind shear and low-level vorticity to represent tropical cyclone genesis climatology. The index was able to reproduce key features of observed genesis climatology. Since then, several other indices have been created using different predictors or different functional dependences (DeMaria et al. 2001; Royer et al. 1998; Sall et al. 2006; Bye and Keay 2008; Kotal et al. 2009; Murakami and Wang 2010; Bruyère et al. 2012; Tang and Emanuel 2012; Holland and Bruyère 2014; Tang and Camargo 2014). In this study, we focus on two of these indices, the Genesis potential index (GPI) and the tropical cyclone genesis index (TCGI). Emanuel and Nolan (2004) developed the original GPI based on potential intensity (PI; Bister and Emanuel 1998) rather than SST in order to avoid the use of a specific threshold that could potentially vary with global warming. PI is the theoretical maximum intensity that a tropical cyclone can reach under specific environmental conditions as defined in Emanuel (1988). A revised version of the GPI, that is used in this study is described in Emanuel (2010). The main difference between the two versions of GPI is the dependence on water vapor, which included the relative humidity on the original GPI, but now considers the entropy deficit (Emanuel 2008). We also consider the tropical cyclone genesis index, or TCGI (Tippett et al. 2011; Camargo et al. 2014). The original TCGI developed in Tippett et al. (2011) compares positively with the GPI. The main difference between the GPI and the TCGI is their different functional dependence; as the TCGI is based on a Poison regression, it has an exponential dependence on the environmental variables. Furthermore, the derivation of the TCGI can be reproduced and redone with any combination of environmental variables and observed TC data. Camargo et al. (2014) showed that in order to replicate the projections of the reduction in the frequency of tropical cyclones under a warming climate, it was necessary to use as predictors for the TCGI the column saturation deficit and PI instead of relative humidity and relative SST, as considered in Tippett et al. (2011). An intercomparison among four genesis indices including the GPI and the TCGI by Menkes et al. (2012) revealed that the impact of using different reanalysis datasets for deriving the indices is much weaker than using different indices. They also showed that the indices have some skill in representing the meridional distribution of genesis. With exception of the TCGI, genesis indices usually have a meridional distribution that is too broad extending too close to the Equator. On the other hand, the GPI has the best interhemispheric balance in the frequency of tropical cyclones. One important drawback from these indices is that they only provide insights on the relationship between the large-scale environment and tropical cyclone genesis, but do not include other important local influences, such as African easterly waves.

First, we examine the changes in the environment of tropical cyclones in the past three decades (1980-2013) in two reanalysis datasets to determine if there has been a poleward shift in the regions favorable for tropical cyclone genesis. Tropical cyclones genesis and intensification are influenced by environmental variables such as vertical wind shear, vorticity, humidity, SST and PI (Gray 1979; Emanuel 1988; Bister and Emanuel 1998). These largescale environmental variables could potentially evolve with the expansion of the tropics, and, therefore, modify global 
tropical cyclone activity. An increase (decrease) in PI, SST, vorticity or humidity (vertical wind shear) is known to be favorable (detrimental) for the formation of tropical cyclone activity. Therefore, we will examine if there has been a poleward shift in each of these variables since 1980 . Second, we analyze the combined changes in environmental conditions by considering changes in the GPI and TCGI over 1980-2013, using the same two reanalysis datasets. Third, we use observations to examine the occurrence of a poleward shift in tropical cyclone genesis over the same time period.

In the next section, we describe the datasets employed and the genesis indices. In Sects. 3 and 4, we examine changes in environmental conditions over the last three decades over the tropics and subtropics using individual environmental variables and genesis indices, respectively. In Sect. 5 we use tropical cyclone observed tracks to determine if there has been a statistically significant poleward shift in tropical cyclone genesis over the last three decades. We summarize our results and state our conclusions in the last section.

\section{Data and methodology}

\subsection{Observations}

The International Best Tracks Archive for Climate Stewardship (IBTrACS; Knapp et al. 2010) is the most complete archive of observed global tropical cyclone best track dataset available online at https://www.ncdc.noaa.gov/ibtracs/. The main advantage of this archive is the consolidation of global tropical cyclone data from various centers at a central location, available as a single file. The inclusion of data from 12 different agencies (see Table 1) introduces heterogeneities due to the differences in operational procedures and observing systems.
The selection of genesis points in the best track data over each basin is not a trivial procedure. Our choice for the definition of tropical cyclone genesis location is the first instance along each tropical cyclone track where the wind speed exceeds 40 knots, which is not the standard wind speed threshold for defining genesis. Usually values near 35 knots are considered. As the uncertainty in the detection of tropical cyclones tends to be larger at lower wind speeds, a higher threshold values increases the confidence in our results without compromising them. We did test several genesis wind speed thresholds and although there is a relationship between the threshold value and the amplitude of the latitude poleward trend, the sign and significance of the trend are not affected by our threshold choice.

\subsection{Reanalysis}

Monthly mean data for two reanalysis data sets in the period 1980-2013 were considered here: the Modern-Era Retrospective Analysis for Research and Applications, or MERRA (horizontal resolution $0.75^{\circ}$ latitude $\times 0.5^{\circ}$ longitude and 42 vertical levels; Rienecker et al. 2011) and European Centre for Medium-Range Weather Forecasts (ECMWF) interim reanalysis, named ERA-Interim (horizontal resolution $0.75^{\circ}$ latitude $\times 0.75^{\circ}$ longitude and 37 vertical levels; Dee et al. 2011). The period 1980-2013 was chosen by taking two issues: (1) the time period in which the best-track dataset is first considered reliable starts in 1980 (satellite era); (2) two time periods of the same length in these three decades: 1980-1996 and 1997-2013. Although reanalysis datasets adequately reproduce many mean patterns of the global climate, each reanalysis product includes systematic errors (Reichler and Kim 2008). The reason for these differences is that reanalysis datasets assimilate data from various observational platforms into a numerical weather prediction model and each reanalysis dataset has a different spatial resolution, spans a different
Table 1 List of the Regional Specialized Meteorology Centers (RSMC) and Tropical Cyclone Warning Centers (TCWC) participating in the WMO Tropical Cyclone Program

\begin{tabular}{lll}
\hline Region & Description & Links to centers (RSMC and TCWC) \\
\hline I-II & Atlantic and Eastern Pacific & US National Hurricane Center (RSMC Miami) \\
III & Central Pacific & US Central Pacific Hurricane Center (RSMC Honolulu) \\
IV & Northwest Pacific & Japan Meteorological Agency (RSMC Tokyo) \\
V & North Indian Ocean & India Meteorological Department (RSMC New Delhi) \\
VI & Southwest Indian Ocean & Météo France (RSMC La Réunion) \\
VII-XI & Southwest Pacific and South- & VII: Australian Bureau of Meteorology (TCWC Perth) \\
& east Indian Ocean & VIII: Indonesian Agency for Meteorology (TCWC Jakarta) \\
& & IX: Australian Bureau of Meteorology (TCWC Darwin) \\
& & X: Papua New Guinea (TCWC Port Moresby) \\
& & XI: Australian Bureau of Meteorology (TCWC Brisbane) \\
XII-XIII & South Pacific & XII: Fiji Meteorological Service (RSMC Nadi) \\
& & XIII: Meteorological Service of New Zealand, Ltd. (TCWC \\
& & Wellington) \\
\hline
\end{tabular}


time period and use different data assimilation schemes. More details on the differences between the reanalysis can be found in Nguyen et al. (2013). Therefore, in order to validate a climate signal estimate, it is crucial to examine multiple reanalysis datasets (Thorne and Vose 2010). We also considered the National Center for Environmental Prediction/ National Center for Atmospheric Research (NCEP/ NCAR) reanalysis in our analysis, however due to significant biases in that dataset for upper tropospheric temperatures and the potential intensity of tropical cyclones, as shown in Kossin (2015), we decided not to include those results here. The TCGI index was also calculated for the Japanese reanalysis dataset (JRA-55; Ebita et al. 2011), but given that the patterns were very similar to the ERAInterim, these results are not shown here either.

\subsection{Genesis potential index}

The formulation of the GPI as presented in Emanuel (2010) is:

$G P I \equiv|\eta|^{3} \chi^{\frac{4}{3}} \operatorname{MAX}\left(\left(P I-35 \mathrm{~ms}^{-1}\right), 0\right)^{2} \times\left(25 \mathrm{~ms}^{-1}+V_{\text {shear }}\right)^{-4}$,

where $\eta$ is the absolute vorticity at $850 \mathrm{hPa}$, PI is the potential intensity, $V_{\text {shear }}$ is the magnitude of the wind shear between 850 and $200 \mathrm{hPa}$. The parameter $\chi$ is defined as

$\chi \equiv \frac{s_{b}-s_{m}}{s_{0}^{*}-s_{b}}$,

where $s_{b}, s_{m}$ are the moist entropies of the boundary layer $\left(s_{b}\right)$ and middle troposphere $\left(s_{m}\right)$, and $s_{0}^{*}$ is saturated moist entropy at the sea surface $\left(s_{0}^{*}\right)$. The nondimensional parameter $\chi$ is a measure of the moist entropy deficit of the middle troposphere, or entropy deficit. $\chi$ becomes larger as the middle troposphere becomes drier.

\subsection{Tropical cyclone genesis index (TCGI)}

The TCGI is constructed using a Poisson regression as described in Tippett et al. (2011). We used here the TCGI formulation discussed in Camargo et al. (2014):

$\mu=\exp \left(b+b_{n}^{\eta}+b_{s} \mathrm{~S}+b_{P I} \mathrm{PI}+b_{v} V_{\text {shear }}+\log \cos \phi\right)$

where $\mu$ is the expected number of tropical cyclones per month, $\phi$ is the latitude, $b$ is a constant and $b_{n}, b_{S}, b_{P I}$, and $\mathrm{b}_{\mathrm{v}}$ are the Poisson regression coefficients. $\eta, \mathrm{S}, P I$, and $V_{\text {shear }}$ are, respectively, the "clipped absolute vorticity" at $850 \mathrm{hPa}$ in $10^{5}$, the saturation deficit, PI, and vertical wind shear between 850 - and 200-hPa levels in $\mathrm{ms}^{-1}$. The saturation deficit is defined as the difference between specific humidity and its saturation value. The regression methodology provides an objective framework for the selection of four environmental variables for the index. One of the original aspects of this index is the use of a "clipped vorticity" to account for the saturation of the low-level absolute vorticity at a certain threshold, as discussed in Tippett et al. (2011).

In order to allow a comparison between the indices (GPI and TCGI) derived from different reanalysis datasets, we used a spatial interpolation to a common $5^{\circ} \times 5^{\circ}$ grid and a temporal calibrating factor, which considers the number of tropical cyclones over 20 years, assuming that the global number of tropical cyclones per year is 90 . The unit for both indices is therefore: the number of TC genesis per 20 years over a $5^{\circ} \times 5^{\circ}$ grid.

\section{Changes in the environment}

Figure 1 presents the differences between 1997 and 2013 and 1980-1996 for MERRA, in entropy deficit $\chi$ (Fig. 1a), PI (Fig. 1b), vertical wind shear (Fig. 1c), vorticity (Fig. 1d), skin temperature (Fig. 1e) and specific humidity at $500 \mathrm{hPa}$ (Fig. 1f). The black line indicates the 95\% confidence level using a t test. Variables are averaged over the peak tropical cyclone seasons, in the Northern Hemisphere during August-October (ASO) and in the Southern Hemisphere January-March (JFM). Figure 1 shows, in agreement with Kossin et al. (2014), large significant changes in large-scale conditions for PI (Fig. 1b) and vertical wind shear (Fig. 1c). A large significant decrease in entropy deficit (Fig. 1a) and PI (Fig. 1b) appears around the Equator, especially over the Pacific Ocean and slightly over the Indian Ocean. In parallel, a significant increase in PI is evident over the subtropics. For the vertical wind shear (Fig. 1c), there is a significant increase around the Equator for the Pacific and Indian Oceans as well, while a decrease, significant at some points, is observed over the subtropics for the Pacific Ocean. These results are consistent with the ones found for ERA-Interim (not shown). These significant changes in entropy deficit, PI and vertical wind shear indicate a displacement of favorable conditions for tropical cyclone activity to higher latitudes, mainly over the Pacific Ocean. The North Atlantic basin changes in this period are significant but different from the Pacific and Indian Oceans, with an increase in PI (Fig. 1b) and a decrease in entropy deficit (Fig. 1a) and in vertical wind shear (Fig. 1c). Therefore, in the North Atlantic basin, there is not a shift towards higher latitudes, but an expansion of the favorable conditions over the tropical latitudes. Consistently with the PI, the skin temperature (Fig. 1e) and the specific humidity (Fig. 1f) increase significantly in the Pacific subtropics and decrease over the Pacific equatorial region, but only significantly over the northern hemisphere tropical region. In contrast, the North Atlantic and the Indian Ocean, the skin temperature and the humidity show a significant increase 


\section{a Entropy deficit}

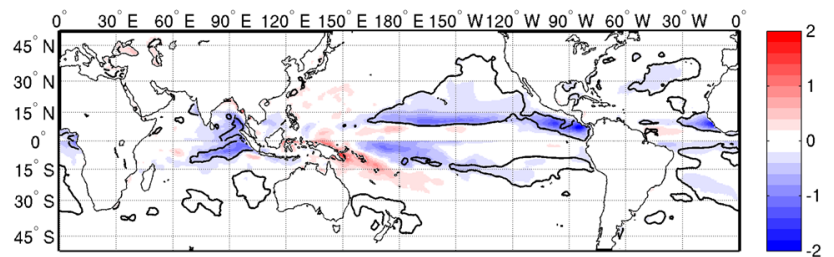

C Vertical wind shear

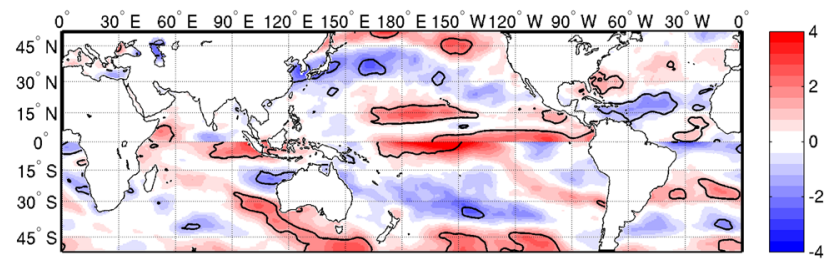

e Skin temperature

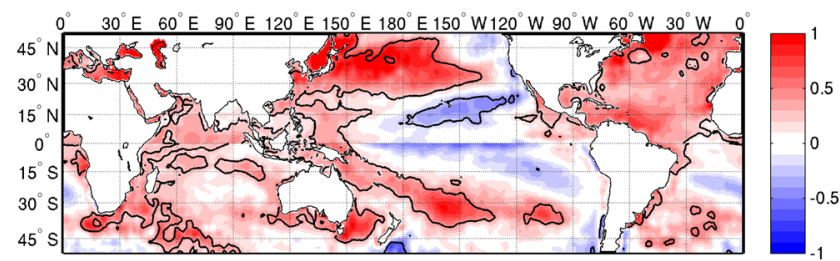

Fig. 1 Seasonal mean differences between 1997 and 2013 and 1980-1996 for: a entropy deficit, b PI, c shear, d vorticity, e skin temperature and $\mathbf{f}$ specific humidity at $500 \mathrm{hPa}$ for MERRA reanaly-

over the tropics and/or subtropics. In the case of the vorticity (Fig. 1d), the changes are more localized. Vorticity changes are very noisy, but there are regions with a significant increase in vorticity on the tropics, such as the North Atlantic. Although the patterns for the vorticity, are not as clear as in the case of PI or the vertical wind shear, it could potentially contribute to the regional migration of tropical cyclone genesis location. Similar results are also found for ERA-Interim (not shown). In summary, favorable conditions for tropical cyclone genesis (PI, vertical wind shear, skin temperature and specific humidity at $500 \mathrm{hPa}$ ) have shifted towards higher latitudes in the Pacific. In contrast, there is an increase in favorable conditions over the tropical North Atlantic, and a mixed picture in the Indian Ocean.

\section{Changes in genesis indices}

\subsection{Tropical cyclone genesis indices climatology}

Figure 2 shows the genesis indices and the observed genesis density climatology for the period 1980-2013 in the peak tropical cyclone season in each hemisphere shown in units of TCs per 20 years per $5^{\circ}$ grid box. The GPI climatology was calculated using the MERRA (Fig. 2a)

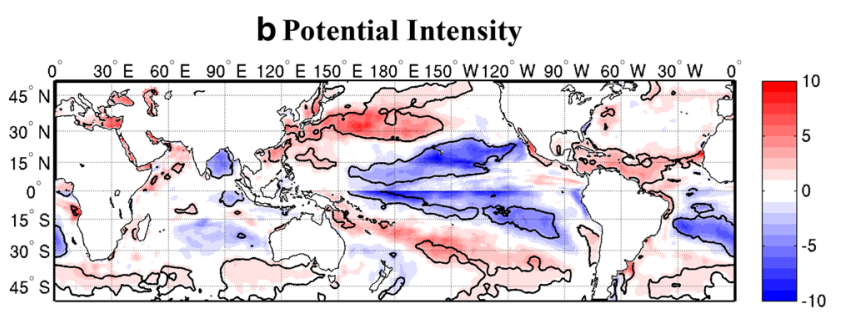

dVorticity

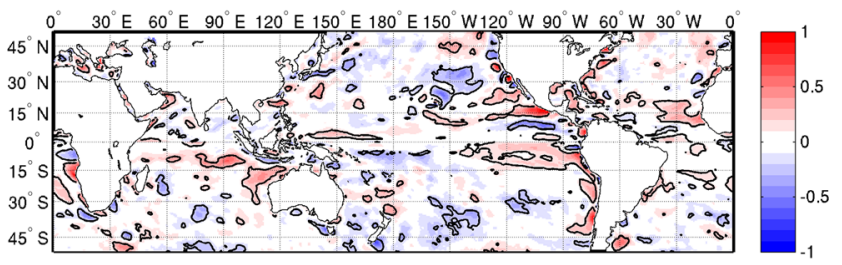

f Q - 500 hPa

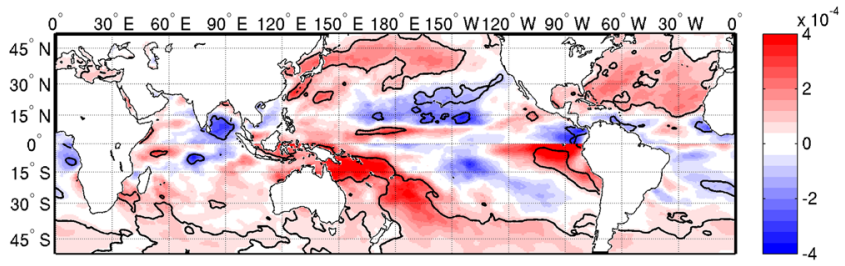

sis, calculated in August-September-October (ASO) for the northern hemisphere and January-February-March (JFM) in the southern hemisphere

and ERA-Interim (Fig. 2b) reanalysis, leading to very similar patterns and amplitudes, with a maximum in the North Atlantic, northeast and northwest Pacific, South Indian Ocean around 12, in the South Pacific around 16 and 10 in the North Indian Ocean (in units TCs per 20 years per $5^{\circ}$ grid). As mentioned above, Menkes et al. (2012) showed that the main differences between tropical cyclone genesis indices are not due to differences in reanalysis datasets but rather on differences in the genesis indices definitions. Indeed, some obvious differences appear between the GPI (Fig. 2a, b) and the TCGI (Fig. 2c) in the amplitude of the regional number of tropical cyclones. TCGI has higher values over most of the basins, with at least three more TCs per 20 years per $5^{\circ}$ grid box than the GPI when using the same reanalysis. The values of the TCGI are close to the observed in the East Pacific, West Pacific, South Indian and eastern North Atlantic basins. On the other hand, in the South Pacific basin the TCGI overestimates the number of number of TCs, while the GPI is closer to the observations. Both GPI and TCGI produce an unrealistic, continuous band of tropical cyclone genesis along the Inter-Tropical convergence zone in the Central Pacific, but this pattern is more pronounced in the TCGI. Both indices have skill 
Fig. 2 Seasonal climatological number of tropical cyclone genesis for the period 1980-2013 derived from the GPI, for a MERRA and b ERAInterim, from the TCGI for $\mathbf{c}$ ERA-Interim, d observations (IBTrACS), show for ASO in the northern hemisphere and JFM in the southern hemisphere. In units of number of tropical cyclones per 20 years by $5^{\circ}$ gridbox

\section{a GPI - MERRA}

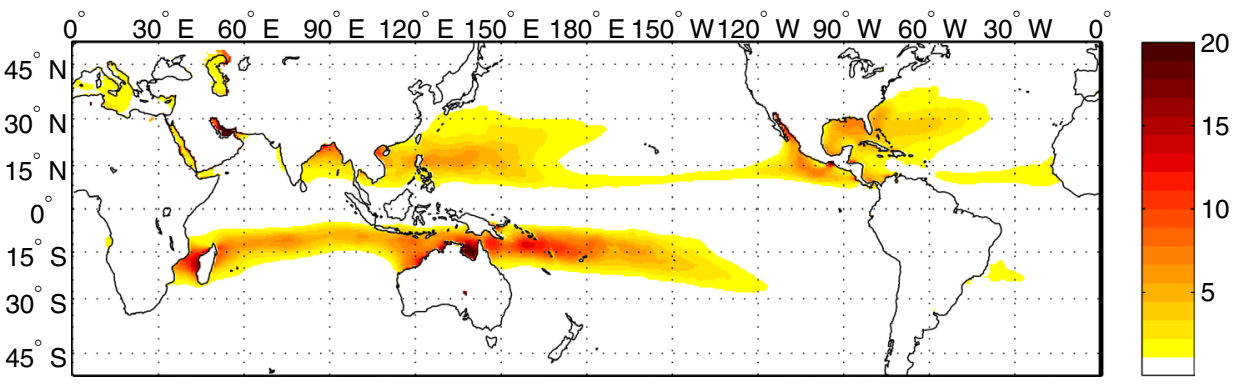

b GPI - ERA-Interim

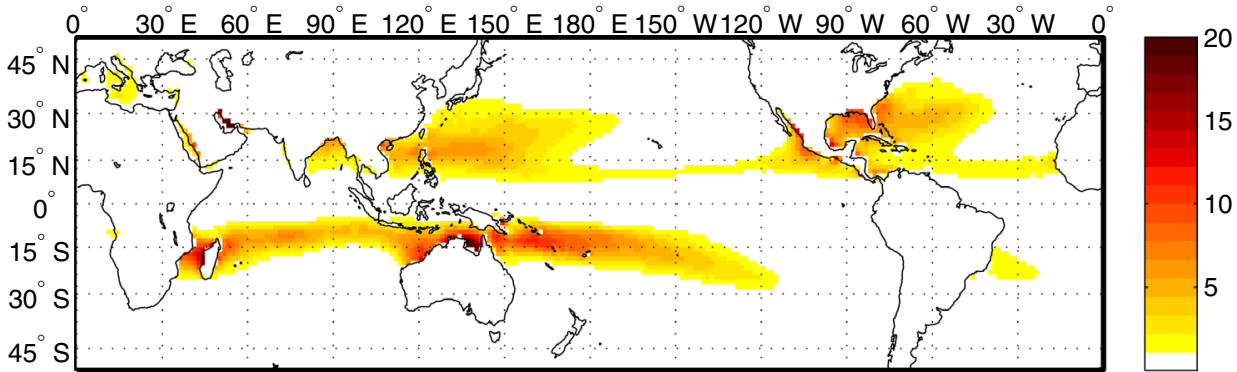

C TCGI - ERA-Interim

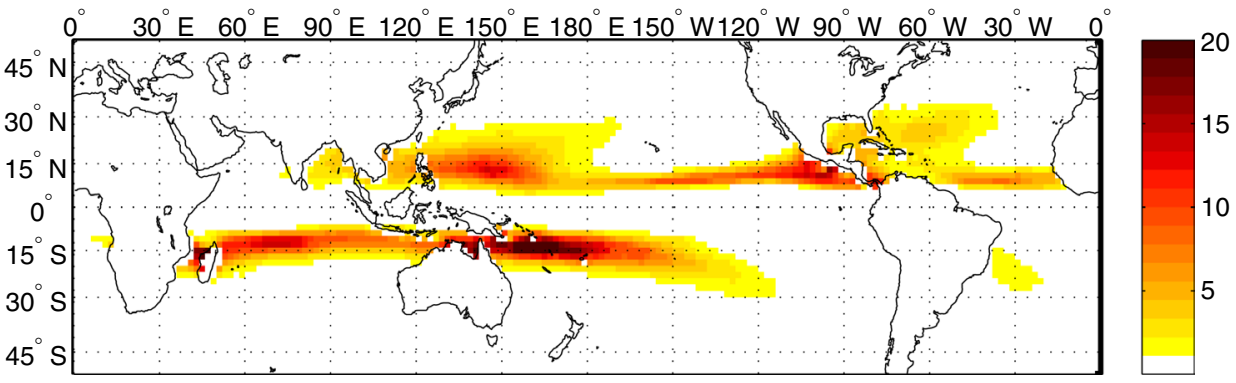

d Observations - IBTrACS

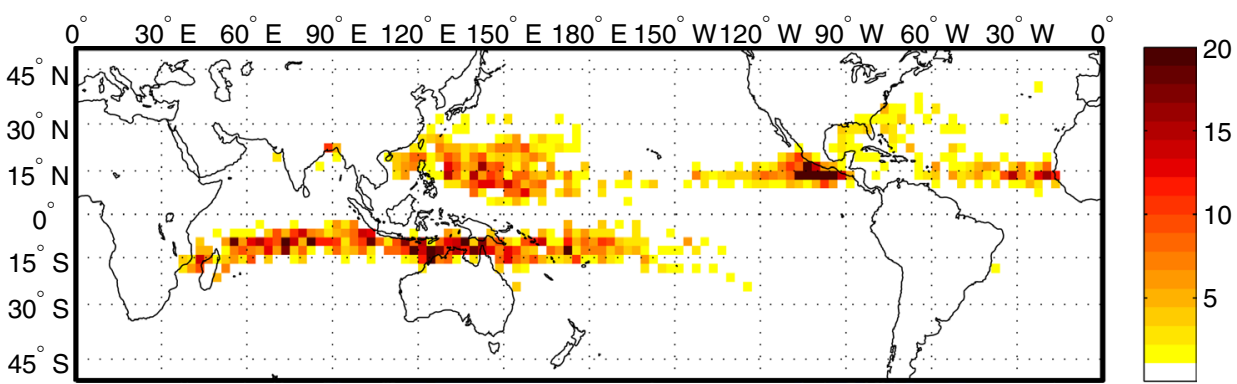

representing the regions with a high potential for tropical cyclone genesis climatologically, however, there are still some biases. This comparison emphasizes the importance of using multiple genesis indices when analyzing trends in tropical cyclone genesis.

\subsection{Changes in tropical cyclone genesis indices over the last decades}

Figure 3 shows the difference in GPI between 1997 and 2013 and 1980-1996 for MERRA (Fig. 3a) and ERAInterim (Fig. 3b), and TCGI for ERA-Interim (Fig. 3c). The 
Fig. 3 Seasonal mean differences of GPI (a MERRA and b ERA-Interim) and TCGI (c ERA-Interim) between 1997 and 2013 and 1980-1996. Black lines indicate the $95 \%$ confidence level using a t test a GPI - MERRA

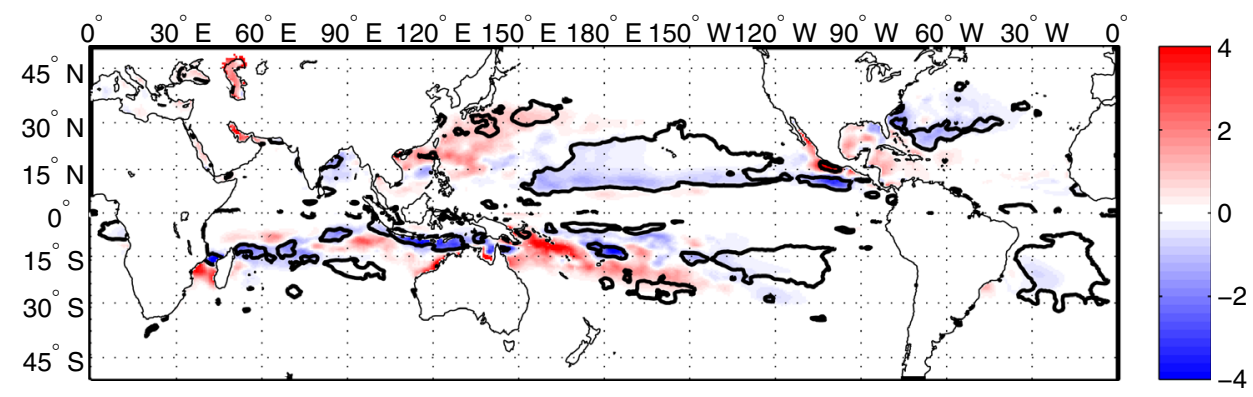

b GPI - ERA-Interim

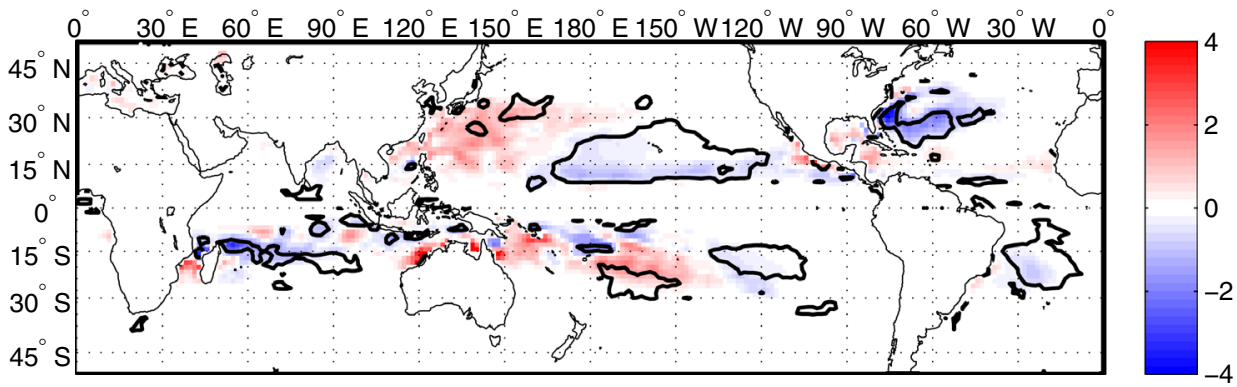

C TCGI - ERA-Interim

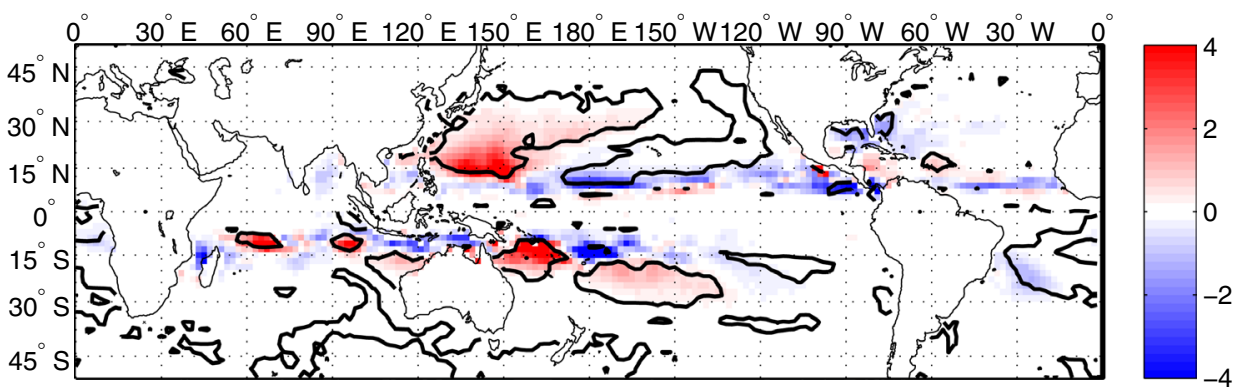

black line indicates where differences are significant at the $95 \%$ confidence level using a $t$ test. The genesis indices difference patterns between these two periods using two reanalysis products are quite similar. In the Pacific subtropics (northwest, northeast and south Pacific) there is a consistent increase of tropical cyclone genesis (3-4 TCs per 20 years per $5^{\circ}$ grid box), while in the tropical Pacific there is a decrease ( $2-3$ genesis per 20 years per $5^{\circ}$ grid box $)$. There is no clear shift in the genesis indices on North Indian Ocean, a result that is not surprising given to the spatial limitations imposed by Asian continent on that region. In South Indian and North Atlantic, the genesis indices show a significant but very small increase at the tropics. We also examined changes in the TCGI for the Japanese reanalysis dataset JRA-55 (Ebita et al. 2011), with similar results to those presented in Fig. 3 (not shown). Therefore, our results are consistent using two different genesis indices and three different reanalysis datasets.
Tropical cyclones genesis and tracks in various basins are often modulated by the phase of the El Niño Southern Oscillation (ENSO; see e.g. Camargo et al. 2010). To test the possible influence of ENSO on the poleward migration of tropical cyclone genesis we derived the differences in the genesis indices excluding El Niño and La Niña years. We used the definition from the Climate Prediction Center (CPC) for El Niño and La Niña seasons based on the Niño3.4 index (Barnston et al. 1997). Separate statistical significance tests were performed for the northern and southern hemispheres at the peak tropical cyclone season in each hemisphere. For the northern (southern) hemisphere, the values of the genesis indices were considered over the ASO (JFM) season. To keep a reasonable data sample size, we only excluded moderate to strong El Niño/La Niña years; when the Oceanic Niño Index (3-month running mean of SST anomalies in the Niño3.4 index region) was above/below $1{ }^{\circ} \mathrm{C}$. Ten (nine) of the 34 seasons were 
excluded in the northern (southern) hemisphere. The resulting differences of the genesis indices obtained excluding the ENSO events were very similar to the original differences, with a significant poleward migration in tropical cyclone genesis over the Pacific Ocean in both hemispheres. We also used a bootstrap test, by choosing randomly 12 out of 17 seasons for each hemisphere, then calculating the differences and their statistical significance. This was repeated 30 times and the poleward shift was always present and statistically significant. Therefore, it is unlikely for ENSO to be the source of the changes in tropical cyclone genesis environment shown in Fig. 3.

In summary, Fig. 3 shows that poleward migration of the tropical cyclone genesis environment is very clear in the Pacific Ocean over the last three decades, but this shift is not present in the other ocean basins. These results are likely not due to ENSO and are consistent with the changes in individual environmental variables described in Sect. 3.

\section{Changes in observed tropical cyclone genesis}

The regions of tropical cyclone activity as defined by the World Meteorological Organization (WMO) are shown in Fig. 4, one or more centers issue tropical cyclone best track dataset in each of these regions as described in Table 1. The amplitude of the meridional trend of tropical cyclone latitude genesis is given in Table 2, as well as the $95 \%$ confidence level of the trend, as defined in
Sect. 2. The annual average latitude of tropical cyclone genesis is derived from 1980 to 2013 , when the data is available for the whole period, as indicated in the legend of Table 2. In addition, Fig. 5 presents the time series of annual-mean latitude of tropical cyclone genesis over West Pacific, East Pacific, South Pacific and North Atlantic basins. Consistent with the results for the genesis indices, Fig. 5 shows a significant poleward trend for the tropical cyclone genesis latitude over the West, East, and South Pacific basins. Over the Western North Pacific (Table 2), all four datasets available in this region present a poleward migration of tropical cyclone genesis ranging between $+72 \mathrm{~km}$ per decade for HKO to $+87 \mathrm{~km}$ per decade for JMA. In the South Pacific basin, Wellington shows a significant poleward trend reaching $+236 \mathrm{~km}$ per decade. Table 2 also presents results from BOM covering the Australian region, which includes parts of the South Pacific and South Indian Oceans. The BOM Australian region includes the South Pacific west of $160^{\circ} \mathrm{E}$ and the South Indian east of $90^{\circ} \mathrm{E}$. Over the Australian region, the data from BOM show a significant positive trend of $57 \mathrm{~km}$ per decade. The East Pacific basin shows a significant positive trend with $+36 \mathrm{~km}$ per decade based on the National Hurricane Center best-track dataset. In the other basins, i.e. Atlantic and Indian Oceans, there are no statistically significant trends. However, the observed trends results are in agreement with the genesis indices results (cf. Fig. 3). For example, in the North Atlantic, Fig. 3a shows an equatorward migration of favorable conditions

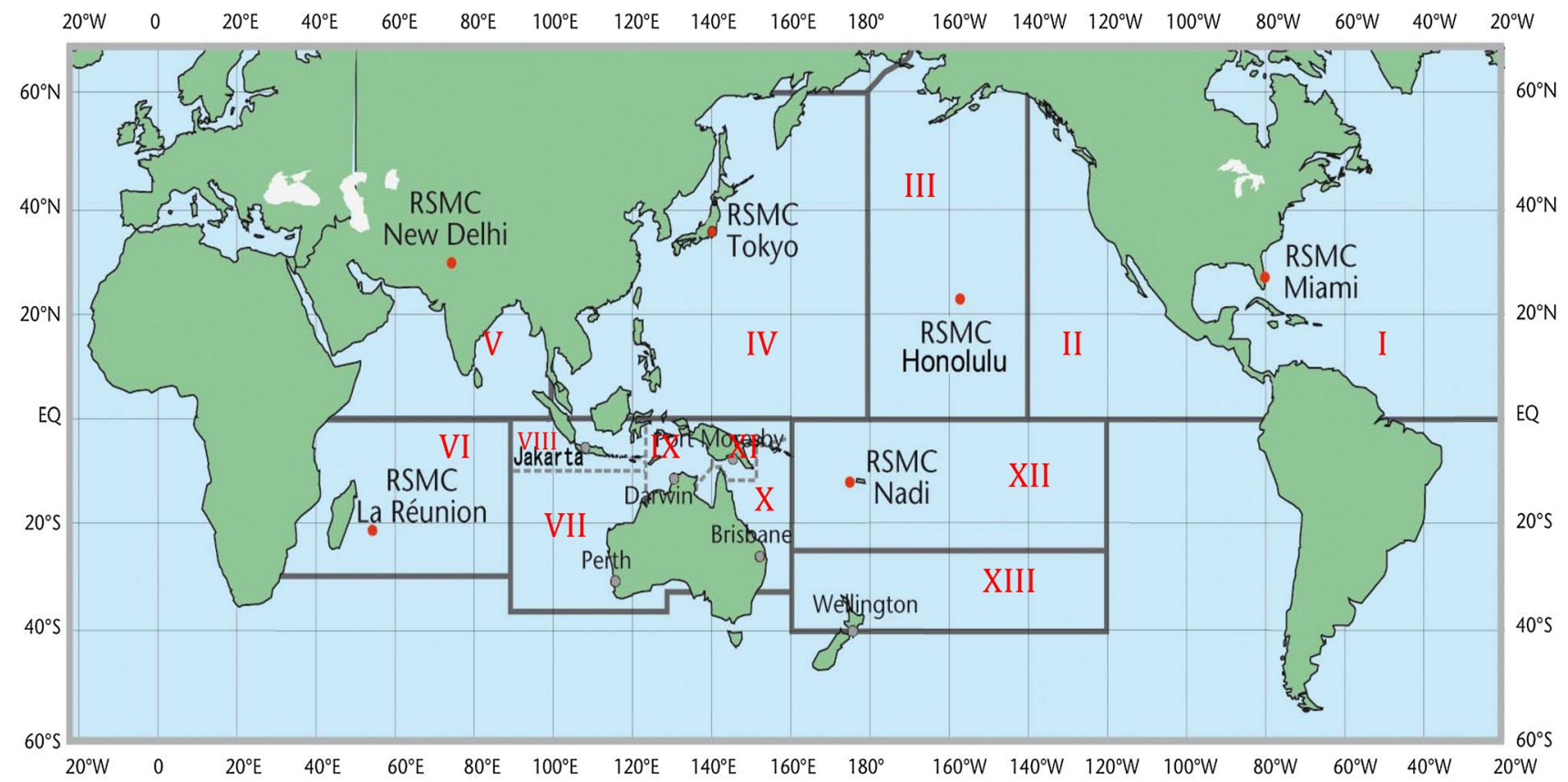

Fig. 4 Global map of tropical centers and their regions of responsibility as defined by the World Meteorological Organization (WMO) with their corresponding regional numbers included in Table 1 
Table 2 Meridional trends of annual average latitude of tropical cyclone genesis (km per decade) and their 95\% confidence levels

\begin{tabular}{|c|c|c|c|c|c|c|c|c|}
\hline & N. Atlantic & East. N. Pac. & Central Pac. & West. N. Pac. & N. Indian & S. Hemisphere & S. Indian & S. Pac. \\
\hline \multicolumn{9}{|c|}{ Best-track genesis (1980-2013)>39 knots } \\
\hline HURDAT & $-110 \pm 116$ & $+36 \pm 35$ & & & & & & \\
\hline Honolulu & & & $-42 \pm 188$ & & & & & \\
\hline JTWC & & & & $+86 \pm 64$ & $-78 \pm 92$ & $+10 \pm 42$ & & \\
\hline JMA & & & & $+87 \pm 61$ & & & & \\
\hline $\mathrm{HKO}$ & & & & $+72 \pm 58$ & & & & \\
\hline CMA & & & & $+86 \pm 55$ & & & & \\
\hline New Delhi & & & & & $-60 \pm 130$ & & & \\
\hline La Réunion & & & & & & & $+24 \pm 65$ & \\
\hline $\mathrm{BOM}^{\mathrm{a}}$ & & & & & & & $+57 \pm 29$ & \\
\hline Wellington & & & & & & & & $+236 \pm 186$ \\
\hline Nadi & & & & & & & & $+45 \pm 198$ \\
\hline
\end{tabular}

Best-track trends are based on time series over the period 1980-2013, Honolulu (1980-2003), New Delhi (1990-2013), La Réunion (19812013), BOM (1984-2013), and Nadi (1994-2013). Positive (negative) trends indicate poleward (equatorward) trends in either hemisphere. None of the time series exhibit AR(1) behavior based on a Durbin-Watson test, except in the cases of BOM and Wellington, which shows the 95\% confidence interval adjusted for autocorrelation

Bold numbers indicate significant trends

${ }^{a}$ The trends for BOM are derived over the vicinity of Australia, which includes part of the South Pacific and South Indian Oceans
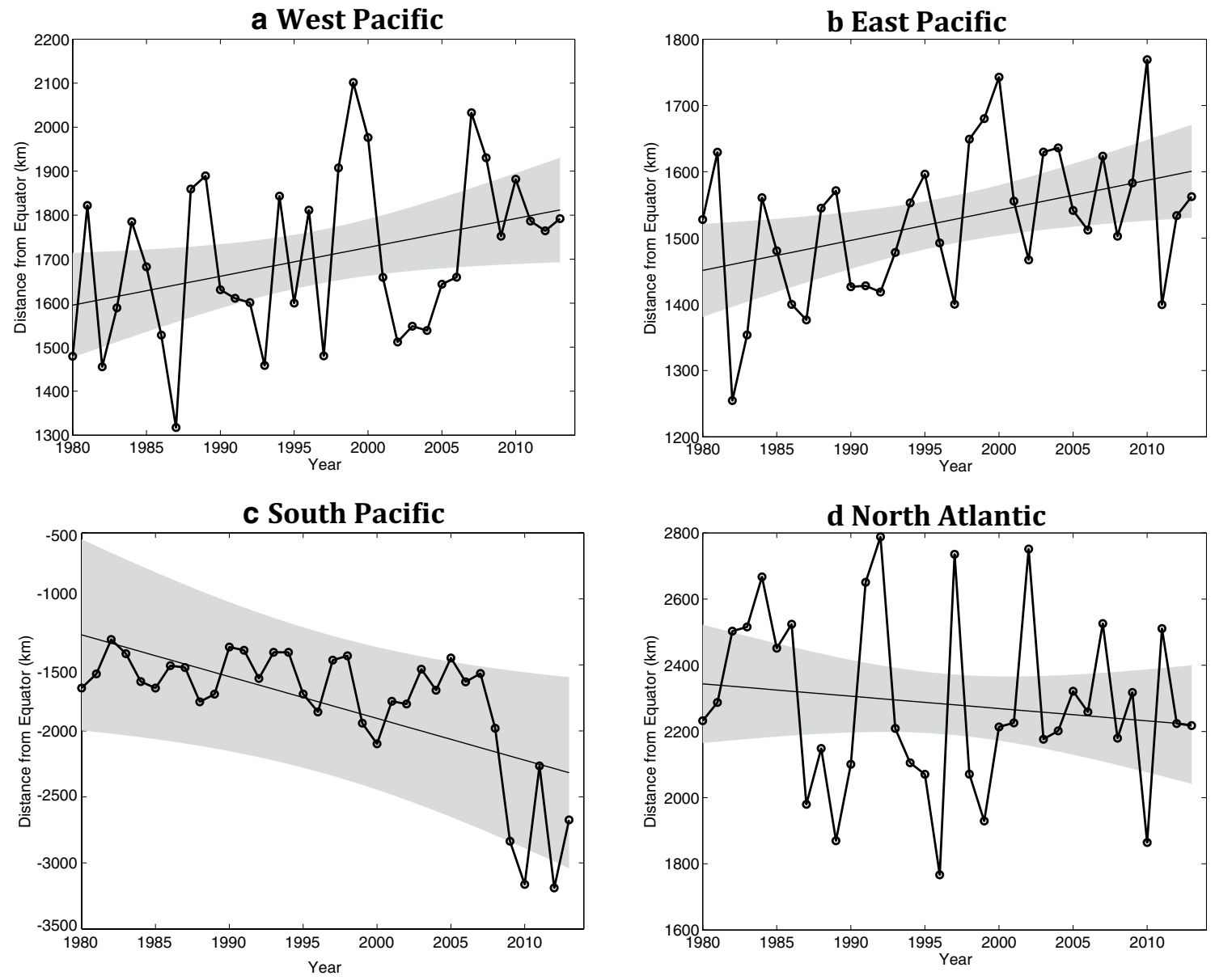

Fig. 5 Time series of annual-mean latitude of tropical cyclone genesis calculated from the best-track archive IBTrACS from 1980 to 2013 for: a West Pacific basin (JTWC), b East Pacific basin (HUR-

DAT), c South Pacific basin (Wellington) and d North Atlantic basin (HURDAT). Linear trend lines are presented with their 95\% twosided confidence intervals 
for tropical cyclone genesis, in agreement with the negative trend of $-110 \mathrm{~km}$ per decade (Table 2; Fig. 5d).

\section{Summary and conclusions}

In this study, we examine if the poleward migration in latitude of lifetime-maximum intensity of tropical cyclones observed by Kossin et al. (2014) over the last decades is related to a poleward migration in global tropical cyclone genesis.

In the first part of the study, we use two reanalysis datasets to look at the changes in the environment (MERRA and ERA-Interim) in six environmental variables known to modulate tropical cyclone genesis. Then we examine combinations of these variables in two genesis indices to examine the possible changes in potential tropical cyclone genesis associated with the changes in the environment. Finally, we compare the storms genesis locations to the changes in the environment using the global best track archive IBTrACS. The results show:

1. Favorable values of PI, vertical wind shear, skin temperature and specific humidity at $500 \mathrm{hPa}$ are moving towards higher latitude in the two reanalysis datasets over the last decades. This poleward migration of the favorable conditions for tropical cyclone genesis is particularly noticeable over the Pacific Ocean.

2. Genesis indices show a migration of the favorable areas for tropical cyclone genesis towards higher latitudes for the East, West and Pacific basins using multiple reanalysis datasets for two genesis indices (GPI and TCGI).

3. The observations show a significant poleward trend of tropical cyclone genesis latitude for the East, West and South Pacific basins.

Our results are consistent with the findings by Kossin et al. $(2014,2016)$ for the western North Pacific, where observations and simulations show a poleward migration of genesis and lifetime-maximum intensity latitude in the present climate. Kossin et al. (2016) also showed that the western North Pacific poleward migration is projected to continue in the future under a warming climate. As new model projections become available, it will be important to analyze genesis, lifetime maximum intensity and tropical cyclone exposure poleward trends over all basins to determine their occurrence and robustness.

In summary, we showed that in addition to a poleward migration of tropical cyclones LMI, there is also a poleward migration of tropical cyclone genesis over the Pacific basins. This finding could be an indication of a more general change: a migration in tropical cyclones tracks. To test this hypothesis, we derived the annual-mean latitude of tropical cyclone genesis over the time period used by Kossin et al. (2014). Then, we compared these results to the annual-mean latitude in LMI over the three Pacific basins. A similar rate in migration could indicate that the changes in the environment are affecting the overall tropical cyclone tracks. However, these rates are not in agreement among the different basins. This does not necessarily mean though that this hypothesis is not valid due to the uncertainties in the best-track datasets. We also would like to explore more in depth in a future study the characteristics of the environmental changes. In particular, it would be important to determine if these changes are just a poleward translation of favorable conditions or if we also see a change in the mean values characterizing the environment. For example, if there is a shift to higher values of PI at higher latitudes, is there also a trend towards higher PI values prior to the shift to these higher latitudes? The answer to this question would determine if other track characteristics have also been modified, such as the storm translational speed, the TC lifetime and the track recurvature location.

Acknowledgements The authors would like to thank Dr. Kossin and Dr. Vimont for their input and guidance. They also would like to thank Dr. Emanuel for providing the genesis potential index datasets. The authors would like to thank an anonymous reviewer for its very insightful comments. Finally, we would like to thank Erin Thomas for the English corrections. The reanalysis datasets were acquired from the Climate Data Guide and the Research Data Archive, developed by the University Corporation for Atmospheric Research (UCAR) which, includes the National Center for Atmospheric Research (NCAR). The reanalysis MERRA was acquired thanks to the dissemination of the data by the Global Modeling Assimilation Office (GMAO) and the Goddard Earth Sciences (GES) Data and Information Services Center (DISC). ERA-Interim data was obtained from the European Center for Medium-range Weather Forecast (ECMWF) data server. SJC acknowledges support from NOAA Grant NA11OAR4310093.

\section{References}

Barnston AG, Chelliah M, Goldenberg SB (1997) Documentation of a highly ENSO-related SST region in the equatorial Pacific. Atmos Ocean 35:367-383

Bister M, Emanuel KA (1998) Dissipative heating and hurricane intensity. Meteorol Atmos Phys 65:223-240

Bruyère CL, Holland GJ, Towler E (2012) Investigating the use of a genesis potential index for tropical cyclones in the North Atlantic Basin. J Clim 25:8611-8626

Bye J, Keay K (2008) A new hurricane index for the Caribbean. Interscience 33:556-560

Camargo SJ, Sobel AH, Barnston AG, Klotzbach PJ (2010) The influence of natural climate variability, and seasonal forecasts of tropical cyclone activity. In: Chan JCL, Kepert JD (eds) Global perspectives on tropical cyclones, from science to mitigation, 2nd edition, World Scientific Series on Earth System Science in Asia, vol 4, Chap 11, pp 325-360. ISBN 978-981-4293-47-1

Camargo SJ, Tippett MK, Sobel AH, Vecchi GA, Zhao M (2014) Testing the performance of tropical cyclone genesis indices in future climates using the HIRAM model. J Clim 27:9171-9196. doi:10.1175/JCLI-D-13-00505.1 
Colbert AJ, Soden BJ, Vecchi GA, Kirtman BP (2013) The impact of anthropogenic climate change on North Atlantic tropical cyclone tracks. J Clim 26:4088-4095

Dee DP, Uppala SM, Simmons AJ, Berrisford P, Poli P, Kobayashi S, Andrae U, Balmaseda M A, Balsamo G, Bauer P, Bechtold P, Beljaars ACM, van de Berg L, Bidlot J, Bormann N, Delsol C, Dragani R, Fuentes M, Geer AJ, Haimberger L, Healy SB, Hersbach H, Hólm EV, Isaksen L, Kållberg P, Köhler M, Matricardi M, McNally AP, Monge-Sanz BM, Morcrette J-J, Park B-K, Peubey C, de Rosnay P, Tavolato C, Thépaut J-N, Vitart F (2011) The ERA-Interim reanalysis: configuration and performance of the data assimilation system. Q J R Meteorol Soc 137:553-597. doi:10.1002/qj.828

DeMaria M, Knaff JA, Conell BH (2001) A tropical cyclone genesis parameter for the tropical Atlantic. Weather Forecast 16:219-233

Ebita A, Kobayashi S, Ota Y, Moriya M, Kumabe R, Onogi K, Harada Y, Yasui S, Miyaoka K, Takahashi K, Kamahori H, Kobayashi C, Endo H, Soma M, Oikawa Y, Ishimizu T (2011) The Japanese 55-year reanalysis "JRA-55": an interim report. Sci Online Lett Atmos 7:149-152. doi:10.2151/sola.2011-038

Emanuel KA (1988) The maximum intensity of hurricanes. J Atmos Sci 45:1143-1155. doi:10.1175/1520-0469(1988)045<1143:TMIO $\mathrm{H}>2.0 . \mathrm{CO} ; 2$

Emanuel K (2008) The Hurricane-climate connection. Bull Amer Meteorol Soc 89:ES10-ES20

Emanuel K (2010) Tropical cyclone activity downscaled from NOAA-CIRES reanalysis, 1908-1958. J Adv Model Earth Syst 2. doi:10.3894/JAMES.2010.2.1

Emanuel KA, Nolan DS (2004) Tropical cyclone activity and the global climate system. Preprints, 26th Conf. on Hurricanes and Tropical Meteorology, Miami, FL, Amer. Meteor. Soc., 10 A.2. http://ams.confex.com/ams/pdfpapers/75463.pdf

Gray WM (1979) Hurricanes: their formation, structure and likely role in the tropical circulation. Meteorol Trop Oceans, D. B. Shaw, Ed., Royal Meteorological Society, 155-218

Holland GJ, Bruyère CL (2014) Recent intense hurricane response to global climate change. Clim Dyn 42:617-627

Kamahori H, Yamazaki N, Mannoji N, Takahashi K (2006) Variability in intense tropical cyclone days in the western North Pacific. Sci Online Lett Atmos 2:104-107

Knapp KR, Kruk MC (2010) Quantifying interagency differences in tropical cyclone best-track wind speed estimates. Mon Weather Rev 138(4):1459-1473

Knapp KR, Kruk MC, Levinson DH, Diamond HJ, Neumann CJ (2010) The international best track archive for climate Stewardship (IBTrACS). Bull Am Meteorol Soc 91:363-376

Kossin JP (2015) Validating atmospheric reanalysis data using tropical cyclones as thermometers. Bull Amer Meteorol Soc 96:1089-1096

Kossin JP, Olander TL, Knapp KR (2013) Trend analysis with a new global record of tropical cyclone intensity. J Clim 26:9960-9976

Kossin JP, Emanuel KA, Vecchi GA (2014) The poleward migration of the location of tropical cyclone maximum intensity. Nature 509:349-352. doi:10.1038/nature13278

Kossin JP, Emanuel KA, Camargo SJ (2016) Past and projected changes in western North Pacific tropical cyclone exposure. J Clim 29:5725-5739
Kotal SD, Kundu PK, Roy Bhowmik SK (2009) Analysis of cyclogenesis parameter for developing and nondeveloping low-pressure systems over the Indian Sea. Nat Hazards 50(2):389-402. doi:10.1007/s11069-009-9348-5

Lander MA (2008) A comparison of typhoon best-TRACK data in the western North Pacific: Irreconcilable differences. 28th Conf. on Hurricanes and Tropical Meteorology, Orlando, FL, Am. Meteorol. Soc., 4B2. http://ams.confex.com/ams/28Hurricanes/techprogram/paper_137395.htm

Lucas C, Timbal B, Nguyen H (2014) The expanding tropics: a critical assessment of the observational and modeling studies. WIREs. Clim Change 5:89-112

Menkes CE, Lengaigne M, Marchesiello P, Jourdain NC, Vincent EM, Lefevre J, Chauvin F, Royer JF (2012) Comparison of tropical cyclogenesis indices on seasonal to interannual timescales. Clim Dyn 38:301-321. doi:10.1007/s00382-011-1126-x

Murakami H, Wang B (2010) Future change of North Atlantic tropical cyclone tracks: projection by a $20-\mathrm{km}$-mesh global atmospheric model. J Clim 23:2699-2721

Nguyen H, Evans A, Lucas C, Smith I, Timbal B (2013) The Hadley circulation in reanalyses: climatology, variability, and change. $\mathbf{J}$ Clim 26:3357-3376

Reichler T, Kim J (2008) Uncertainities in the climate mean state of global observations, reanalyses, and the GFDL climate model. J Geophys Res 113:D05106. doi:10.1029/2007JD009278

Rienecker MM, Suarez MJ, Gelaro R, Todling R, Bacmeister J, Liu E, Bosilovich MG, Schubert SD, Takacs L, Kim G-K, Bloom S, Chen J, Collins D, Conaty A, da Silva A, Gu W, Joiner J, Koster RD, Lucchesi R, Molod A, Owens T, Pawson S, Pegion P, Redder CR, Reichle R, Robertson FR, Ruddick AG, Sienkiewicz M, Woollen J (2011) MERRA: NASA's modern-era retrospective analysis for research and applications. J Clim 24(14):3624-3648

Royer J-F, Chauvin F, Timbal B, Araspin P, Grimal D (1998) A GCM study of the impact of greenhouse gas increase on the frequency of occurrence of tropical cyclone. Clim Change 38:307-343

Sall SM, Sauvageot H, Gaye AT, Viltard A, de Felice P (2006) A cyclogenesis index for tropical Atlantic off the African coasts. Atmos Res 79:123-147

Tang B, Camargo SJ (2014) Environmental control of tropical cyclones in CMIP5: a ventilation perspective. J Adv Model Earth Syst. doi:10.1002/2013MS000294

Tang B, Emanuel K (2012) Sensitivity of tropical cyclone intensity to ventilation in an axisymmetric model. J Atmos Sci 69:2394-2413

Taylor KE, Stouffer RJ, Meehl GA (2012) An overview of CMIP5 and the experiment design. Bull Am Meteorol Soc 93:485-498. doi:10.1175/BAMS-D-11-00094.1

Thorne PW, Vose RS (2010) Reanalyses suitable for characterizing long-term trends. Bull Meteorol Soc 91:353-361

Tippett MK, Camargo SJ, Sobel AH (2011) A Poisson regression index for tropical cyclone genesis and the role of large-scale vorticity in genesis. J Clim 24:2335-2357. doi:10.1175/2010J CLI3811.1 